\section{Chronic lymphoedema caused by recurrent infections in a patient with allergic hand eczema}

\author{
Beatrice Dyring-Andersen, Lone Skov, \\ Peter Jensen \\ Department of Dermato-Allergology, \\ Copenhagen University Hospital \\ Gentofte, Copenhagen, Denmark
}

\begin{abstract}
Allergic contact dermatitis is very common and may be complicated by secondary infections. Chronic lymphoedema is a potentially debilitating condition, which may occur due to secondary infections or the dermatitis itself. The problem of chronic lymphoedema following allergic contact dermatitis has been infrequently reported. We report a case of a 47-yearold woman with severe allergic contact dermatitis complicated by chronic, intractable lymphoedema of the hands and forearms. This case report reminds us that allergic hand dermatitis may be complicated by a chronic and debilitating state of lymphoedema. Also, it underlines the importance of fast and adequate treatment of both the dermatitis and the secondary infections.
\end{abstract}

\section{Introduction}

Allergic contact dermatitis is a common disease, which may be complicated by secondary infections. Chronic lymphoedema due to destruction of lymphatic vessels is a potentially debilitating condition, which may occur due to secondary infections or the dermatitis itself. The problem of chronic lymphoedema following allergic contact dermatitis has been infrequently reported..$^{1-5}$

\section{Case Report}

We report a case of a 47-year-old woman with severe allergic contact dermatitis complicated by chronic lymphoedema. At time of referral, clinical examination showed acute eczema on the hands. Patch testing was performed with the European Standard series using Finn Chambers ${ }^{\odot}$ (Epitest., Oy, Finland) on Scanpor tape ${ }^{\odot}$ (Norgesplaster A/S, Alpharma, As, Norway). The patch tests were applied to the upper back and occluded for two days and readings were done on D2, D3 and D7. There were positive reactions to formalde- hyde, chromium, balsam of Peru, sesquiterpene lactone mix and colophonium. All reactions were of clinical relevance for the patient, who worked as a kindergarten teacher.

The patient was instructed to avoid the known allergens and treatment with topical steroid was initiated but with little effect on the dermatitis. Over the following months she had numerous secondary infections, which necessitated several courses of systemic antibiotic therapy. To achieve disease control, the patient received therapy with per oral prednisolone followed by treatment with azathioprine. However, because of her Compositae allergy, the hand eczema flared every summer and despite systemic anti-inflammatory treatment it was often complicated by secondary infections (Staphylococcus aureus) with lymphangitis. Every infectious episode was treated with relevant antibiotics often in combination with potassium permanganate baths. In spite of this, the patient developed chronic lymphoedema of the hands and forearms (Figure 1). The diagnosis was confirmed by a lymphoscintigraphy which showed complete functional failure of the peripheral lymphatic vessels. Now, two years later, the patient is being treated with compression garments with limited effect. She remains unable to work as a kindergarten teacher and she was also unable to complete a work rehabilitation programme due to her swollen and painful arms.

\section{Discussion}

We describe here a case of a chronic debilitating lymphoedema of the hands and forearms secondary to recurrent infections in a woman with severe, intractable allergic hand dermatitis. Chronic lymphoedema secondary to allergic or irritant contact dermatitis has been infrequently reported. ${ }^{1-5}$ Approximately half of the patients have no history of infection involving the affected areas prior to the debut of lymphoedema. ${ }^{1-5}$ Therefore, one may give consideration to the aetiology of the lymphoedema and the pathology involved in the destruction of the lymphatic vessels. A plausible mechanism in the present case could be obliterating bacterial lymphangitis which may lead to lymphatic insufficiency in patients with recurrent secondary infections. In patients with chronic lymphoedema without recurrent infections, damage to the lymphatic vessels may be caused by the harmful effect of the dermatitis itself. ${ }^{1,2}$

This case report reminds us that allergic hand dermatitis may be complicated by a chronic and debilitating state of lymphoedema. Also, it underlines the importance of fast and adequate treatment of both the dermatitis and the secondary infections.
Correspondence: Peter Jensen, Department of Dermato-Allergology, Copenhagen University Hospital Gentofte Niels Andersens Vej 65, DK-2900 Hellerup, Copenhagen, Denmark.

Tel. +45.3977.7538 - Fax: +45.3965.7137.

E-mail: peterj01@geh.regionh.dk

Key words: allergic contact dermatitis, hand eczema, lymphoedema, lymphangitis, recurrent infections.

Acknowledgments: Peter Jensen was supported by a grant from the Michaelsen Foundation and Beatrice Dyring-Andersen was supported by a grant from the Aage Bang Foundation.

Conflict of interest: the authors report no conflicts of interest.

Received for publication: 20 June 2011.

Accepted for publication: 22 June 2011.

This work is licensed under a Creative Commons Attribution NonCommercial 3.0 License (CC BYNC 3.0).

(C) Copyright B. Dyring-Andersen et al., 2011

Licensee PAGEPress, Italy

Dermatology Reports 2011; 3:e11

doi:10.4081/dr.2011.e11

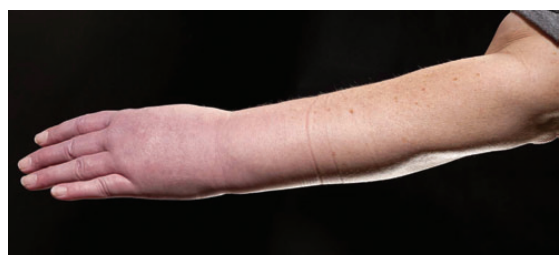

Figure 1. Chronic lymphoedema of the hand and forearm.

\section{References}

1. Worm AM, Staberg B, Thomsen K. Persistant oedema in allergic contact dermatitis. Contact Dermatitis 1983;9:517-8.

2. Pearce VJ, Mortimer PS. Hand dermatitis and lymphoedema. Br J Dermatol 2009; 161:177-80.

3. Fitzgerald DA, English JS. Lymphoedema of the hands as a complication of chronic allergic contact dermatitis. Contact Dermatitis 1994;30:310.

4. Lynde CW, Mitchell JC. Unusual complication of allergic contact dermatitis of the hands -- recurrent lymphangitis and persistent lymphoedema. Contact Dermatitis 1982;8:279-80.

5. Proske S, Uter W, Schwanitz HJ. [Secondary lymphedema of the hand as a complication of recurrent erysipelas in irritant contact dermatitis]. Hautarzt 2001;52:888-90. 